\title{
The molecular genetics of the bithorax complex of Drosophila: characterization of the products of the Abdominal-B domain
}

Susan E. Celniker, Dan J. Keelan, and E.B. Lewis

Division of Biology, California Institute of Technology, Pasadena, California 91125 USA

In Drosophila the Abdominal-B $(A b d-B)$ domain of the bithorax complex specifies the identities of several posterior abdominal segments, comprises homeo-protein-coding regions and cis-regulatory regions, and extends from infra-abdominal-5 (iab-5) to iab-8, inclusive. Mutations that eliminate the $A b d-B$ domain act as late embryonic lethals and result in transformations of posterior abdominal segments toward more anterior ones. The $\boldsymbol{A b d}$ - $\boldsymbol{B}$ domain gives rise to a minimum of five homeo-box-containing transcripts, $7.8,4.7,4.3,3.7$, and 3.3 $\mathrm{kb}$ in length. We examined the structure of the $A b d-B$ domain by sequencing two $A b d-B$ cDNA clones derived from the 4.3- and the 4.7- $\mathrm{kb}$ transcripts and the corresponding genomic DNA. The domain spans $\sim 100 \mathrm{~kb}$ and contains at least eight exons. The 4.7- and 4.3-kb transcripts contain an open reading frame capable of encoding a 54-kD protein. A portion of the deduced protein-coding sequence common to all of the $A b d-B$ transcripts was cloned into an expression vector. The resultant fusion protein then was used to derive a monoclonal antibody specific to $A b d-B$. By use of that antibody, we identified two embryonic $A b d-B$ proteins, 54 and $36 \mathrm{kD}$ and determined the sum of their segmental distribution by immunohistochemical analysis of whole-mounted embryos and immunofluorescent analysis of dissected embryonic nervous systems. The proteins are distributed in the fourth to the ninth abdominal segments [parasegments (PS) 10-15] inclusive. Embryos homozygous for $P o l y c o m b(P c)$ show labeling over almost the entire embryo, whereas embryos deficient for the $A b d-B$ domain show no detectable labeling.

[Key Words: Embryonic development; bithorax complex; immunohistochemistry; DNA sequence; homeo box; Polycomb]

Received April 14, 1989; revised version accepted June 16, 1989.

A number of determinative events that control the early embryonic development of Drosophila are well characterized genetically. Two types of zygotically active genes are required: segmentation genes, that control the number and polarity of the body segments (NüssleinVolhard and Wieschaus 1980) and homeotic genes that control segmental identity. The latter are represented by genes of the Antennapedia complex (ANT-C) (Kaufman et al. 1980; Garber et al. 1983; Scott et al. 1983) and the bithorax complex (BX-C) (for review, see Duncan 1987). Certain segmentation genes appear to be required for the initiation of homeotic gene expression (Ingham and Martinez-Arias 1986; Ingham et al. 1986; White and Lehmann 1986; for review, see Akam 1987), whereas genes such as Polycomb $(P c)$ (Lewis 1978; Duncan and Lewis 1982) and extra sex combs (esc) (Struhl 1981) seem to be involved in maintaining the spatial pattern of homeotic gene expression once it is established (Struhl and Akam 1985; Wedeen et al. 1986).

The BX-C is essential for specifying the identity of a body region that extends from the posterior portion of the second thoracic segment to the anterior portion of the ninth abdominal segment. The BX-C is organized into three domains designated Ultrabithorax $(U b x), a b$ dominal-A (abd-A), and Abdominal-B $(A b d-B)$ (SanchezHerrero et al. 1985a,b; Tiong et al. 1985) spanning over $300 \mathrm{~kb}$ (Bender et al. 1983; Karch et al. 1985). In the $\mathrm{BX}-\mathrm{C}$ there are three homeo box sequences, one in each domain (Regulski et al. 1985). The homeo box encodes a homeo domain that is a conserved sequence of 60 amino acids with DNA binding abilities (Laughon and Scott 1984; Shepherd et al. 1984; Desplan et al. 1985). The sequential expression of the BX-C genes and their cis-regulatory regions along the anterior/posterior body axis is 
colinear with their order in the chromosome (Lewis 1978). Each of the three homeo-box-containing transcription units is transcribed in a distal to proximal orientation.

The $A b d-B$ domain occupies the distal one-third of the complex (from approximately +100 to +200 on the $\mathrm{BX}-\mathrm{C}$ walk) and is required for specifying the identities of posterior abdominal segments. Mutations that inactivate all the functions of the $A b d-B$ domain are designated $A b d-B$ alleles (nomenclature of Duncan 1987). Mutations that inactivate specific subfunctions are designated infra-abdominal-5 (iab-5), iab-6,iab-7, or iab-8 (Karch et al. 1985). The $i a b-7$ and $i a b-8$ subfunctions also have been referred to as $A b d-B^{m}$ and $A b d-B^{r}$, respectively (Casanova et al. 1986). The effects of these mutations in embryos are defined most readily in terms of a parasegmental unit (PS), which consists of the posterior portion of one body segment and the anterior portion of the next most posterior segment (Lawrence and Martinez-Arias 1985). $A b d-B^{+}$function commences in PS 10 (i.e., the posterior portion of the fourth and anterior portion of the fifth abdominal segment) and extends to PS 15 (i.e., the posterior portion of the eighth and anterior portion of the ninth abdominal segment).

In situ hybridization to embryonic and imaginal tissues reveals that $A b d-B$ transcripts are localized in regions where the $A b d-B$ domain is required in development. Thus, $A b d-B$ transcripts have been detected in the embryonic nervous system in PS 10-PS 14 /Harding et al. 1985; Levine et al. 1985; Regulski et al. 1985; Wedeen et al. 1986). We have shown that a probe derived from the $3^{\prime}$ portion of an $A b d-B$ cDNA detects transcripts in genital discs but not other imaginal discs /Celniker and Lewis 1987). Genital discs are the only imaginal discs found in the abdomen.

More recently, by use of a number of genomic DNA restriction fragments from the $A b d-B$ region as probes, different sets of transcripts have been detected with differential domains of expression (Kuziora and McGinnis 1988; Sanchez-Herrero and Crosby 1988). The transcript sizes and corresponding spatial distribution are as follows: 4.3- and 4.7-kb transcripts localized to PS 10 to PS $15 ; 3.3-, 3.7-$, and $7.8-\mathrm{kb}$ transcripts localized to PS 14 and PS 15. A 4.1-kb cDNA, corresponding to a portion of the $7.8-\mathrm{kb}$ transcript, has been sequenced by DeLorenzi et al. (1988) who show that it can encode a $30-\mathrm{kD}$ or $36-\mathrm{kD}$ homeo protein. This predicted protein would be responsible for proper development of PS 14 of the embryo and the genital disc and its adult derivatives.

Our goal has been to obtain antibodies to proteins from the $A b d-B$ domain and to determine the spatial and temporal distribution of such proteins in the developing organism. We report here the results of the use of a monoclonal antibody to follow the pattern of protein expression in: (1) wild-type embryos; (2) embryos that lack entirely the $A b d-B$ domain; and (3) embryos that overexpress the BX-C genes owing to the virtual lack of Polycomb $b^{+}\left(\mathrm{PC}^{+}\right)$, a negative trans-regulator of the BX-C.

\section{Results}

Sequence analysis of $\mathrm{Abd}-\mathrm{B} c D N A$ clones and the corresponding genomic DNA

To determine the structure of the $A b d-B$ domain and transcripts, we isolated and sequenced embryonic and pupal cDNA clones. We described previously the isolation of cDNA clones from 3- to 12-hr embryonic and 5.5to 7.5-day pupal libraries (Celniker and Lewis 1987). A fragment of genomic DNA, containing the $A b d-B$ homeo box (Regulski et al. 1985) was used to isolate these cDNA clones. The clones hybridize to three genomic EcoRI restriction fragments 15013,5014 , and 5015 ) that span $\sim 9 \mathrm{~kb}$ from about +150 to +159 on the BX-C map (Fig. 1A).

Results from our restriction-fragment analysis and sequencing of genomic and partial cDNA clones (P5 and P3| identify a transcription unit that contains at least five exons. The $A b d-B$ sequence shown in Figure 2, includes the entire P5 cDNA sequence, 5 ' sequence from cDNA P3, and genomic sequence from the region that immediately flanks the $5^{\prime}$ end of the cDNAs. The 5' exon (exon 4 ) is at least $888 \mathrm{bp}$, the three internal exons (exons 5, 6, and 7) are 212, 202, and $215 \mathrm{bp}$, and the last exon (exon 8) is 1913 bp (Fig. 1B). The donor and acceptor sequences are all consensus with the exception of the donor sequence following exon 5 , which begins with a nonconsensus GGT (Table 1). Two of the introns (between exons $5+6$ and $7+8$ ) are micro introns that contain only 84 and $56 \mathrm{bp}$, respectively. The homeo box is encoded by portions of exons 7 and 8 . Thus, the first $132 \mathrm{bp}$ of the homeo box are at the $3^{\prime}$ end of exon 7 . The intron position found in the $A b d-B$ homeo box is identical to that found in the homeo boxes of the labial gene (Mlodzik et al. 1988) and the distal-less gene (Cohen et al. 1989|.

The sequence of the $3^{\prime}$ end of cDNA clone P5 contains a stretch of $17 \mathrm{~A}$ residues. Thirty-six base pairs upstream of the poly(A) tail is a consensus polyadenylation signal sequence, AATAAA (Proudfoot and Brownlee 1976), which presumably corresponds to one of the $3^{\prime}$ ends of $A b d \cdot B$.

\section{Developmental expression of Abd-B RNAs and their relation to the Abd-B cDNAs}

We examined the temporal expression of $A b d-B$ RNAs by use of a fragment from the $3^{\prime}$ end of cDNA P5. This fragment was chosen because it does not contain the homeo box or $M$ repeat and thus should only detect mRNAs transcribed from the $A b d-B$ domain. We detect five RNAs $7.8,4.7,4.3,3.7$, and $3.3 \mathrm{~kb}$ in length. The 7.8-kb RNA is only weakly detectable between 4 to 10 hr of embryonic development (Fig. 3B). The 4.3- and 3.3kb RNAs are expressed predominantly in 4- to $7-\mathrm{hr}$ embryos but can be detected in later embryonic stages as well as in larvae, pupae, and adults (Fig. $3 \mathrm{~A}$ and B). The 


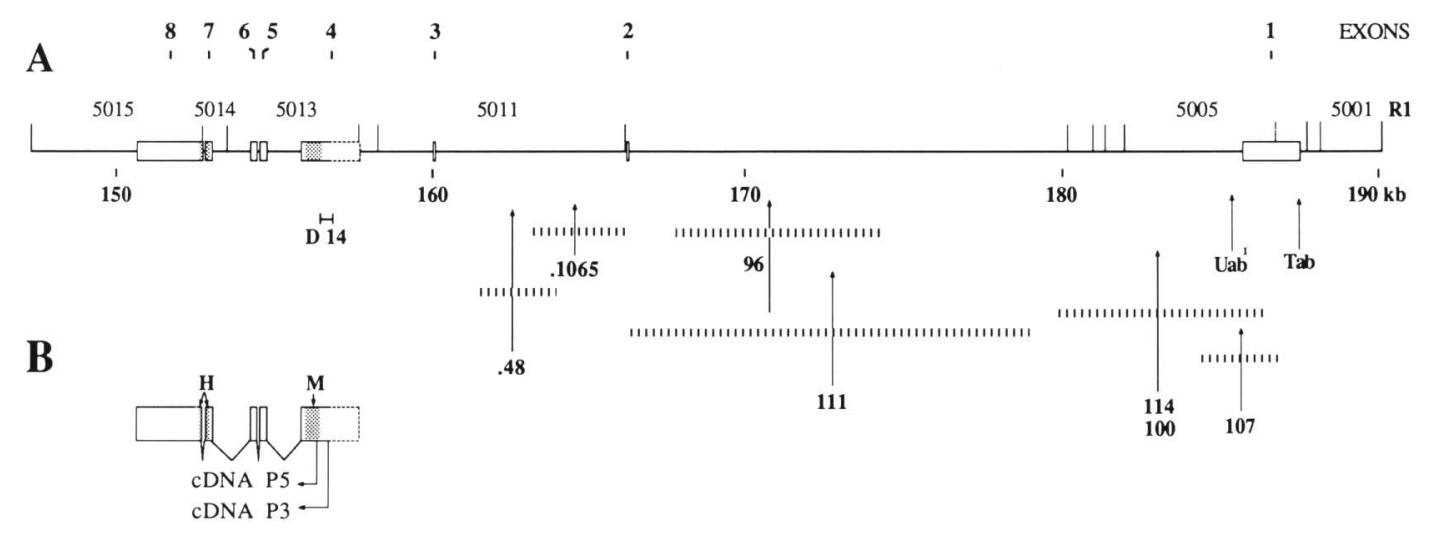

C

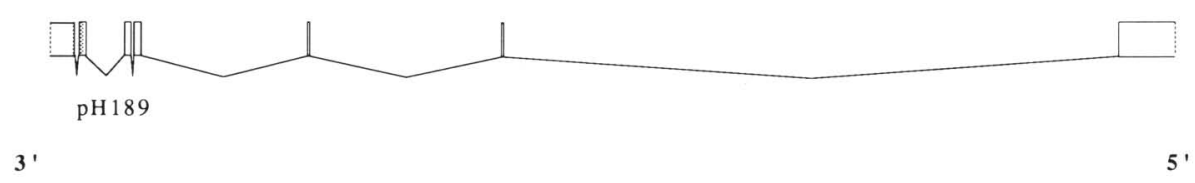

Figure 1. Organization and structure of genomic DNA and representative cDNAs from the distal end of the BX-C. $(A)$ Restriction map of the genomic EcoRI DNA fragments subcloned into pUC18 (some of which are labeled: 5001, etc.). The numbers below the line refer to the BX-C map position according to Karch et al. (1985). A composite of exons (labeled 1-8) (open boxes) identified in this study and by DeLorenzi et al. (1988) are shown. The map positions of $i a b-8(T a b, U a b, 107,114,100,111,96, .1065$, and .48) and iab-7 (D14) mutations are indicated. (B) $A b d-B$ cDNAs (5 and 3) used for sequencing with the positions of the homeo box $(H)$ and the $M$-repeat $(M)$ marked by arrows and hatched boxes. (C) iab-8 cDNA (pH189) sequenced by DeLorenzi et al. (1988).

4.7- and 3.7-kb RNAs are expressed late in embryonic development at $10-13 \mathrm{hr}$ relative to the 4.3 - and the 3.3$\mathrm{kb}$ RNAs and do not appear to persist beyond embryogenesis.

These RNAs have been detected previously by use of genomic restriction fragments from the $A b d-B$ domain (Kuziora and McGinnis 1988; Sanchez-Herrero and Crosby 1988). The estimated sizes of the five transcripts vary within $200 \mathrm{bp}$ but the temporal patterns of expression are in good agreement.

The cDNA clones that we characterized correspond to the 4.3-kb $A b d-B$ transcripts (Fig. 3A) found by Northern analysis to hybridize specifically to the genomic region from + 155.5 to $+157 \mathrm{~kb}$ (Kuziora and McGinnis 1988; Sanchez-Herrero and Crosby 1988). The last four exons (labeled 5-8, Fig. 1A) are common to all five $A b d-B$ RNAs (Kuziora and McGinnis 1988; Sanchez-Herrero and Crosby 1988; S. Celniker, D. Keelan, and E. Lewis, unpubl.) and are known to encode the $3^{\prime}$ portion of the 7.8-kb transcript as sequenced by DeLorenzi et al. (1988) (shown in Fig. 1C). The $\sim 400$-bp difference at the 3 ' ends of the 4.7- and 4.3-kb (4-kb set) and the $3.7-$ and $3.3-\mathrm{kb}$ (3-kb set) transcripts is the result of alternate choices in the site of polyadenylation (data not shown). The $3^{\prime}$ end of the $7.8-\mathrm{kb}$ transcripts has not been determined. We attribute the large differences in sizes of the transcripts $(7.8,4$, and $3 \mathrm{~kb})$ to differences at their $5^{\prime}$ ends, although we have not carried out primer extensions. The $4-\mathrm{kb}$ transcripts are not the product of differential splicing because no acceptor splice sites exist in front of exon 4 /S.
Celniker and D. Keelan, unpubl.). As a result, the 7.8-kb transcript (Fig. 1C) splices exon 3 directly to exon 5 as shown by Delorenzi et al. (1988). Kuziora and McGinnis (1988) used restriction mapping of cDNAs to group the $A b d-B$ transcripts into four classes. They predicted that the 3-kb transcripts also splice exon 3 to exon 5, and we confirmed this by sequencing ( $\mathrm{S}$. Celniker and $\mathrm{D}$. Keelan, unpubl.|. The cDNAs we analyzed are similar in structure to their $\alpha$ class with the exception that, by sequencing, we mapped the presence of two additional exons (exons 6 and 7 ).

\section{Analysis of the derived amino acid sequence}

We identified a long continuous open reading frame (ORF) from nucleotide 513 to 2177 (Fig. 2). There are three in-frame methionines in this ORF. Translation initiated at these methionines would result in proteins of $54,902,43,877$, and 30,198 $\mathrm{kd}$. The codon usage (Staden 1984) of the ORF matches well with the preferred codon bias for Drosophila (K. Burtis, pers. comm.).

The protein sequences contain several hydrophilic regions as revealed by hydrophobicity plots (Hopp and Woods 1981), and there are no predicted membrane spanning domains. The isoelectric points for the predicted proteins are basic $(9.5,9.7$, and 9.9$)$, which results because of the high proportion of lysine, arginine, and histidine residues $(14 \%)$. The predicted $54-\mathrm{kD}$ protein also contains a large number of repetitive amino acid sequences. The amino half of the protein is glutamine- 
1

GGAAAAGTT TGGAAAATTGGATTGACCGAATGAAACTGAAAAAAGCCAATTTGAAATACTGCGTGACTTGCTGAAAAAGAAAAGTGAAAAGAAAACATTAACTGACAAAGGAAAATI TGCAACAACAAAGTGACTCTCTTCGCCCGCTCTTTAGGCAGTGTGCGTGTGTGAGTAAGTCGGCGTGTGCGTGTGACCGCTGAGGCAGCTTTGTGTGCGTGTGCGGTACGCAAATAAAA GGGGCAGAACTCGAGTAAAGGTGCTCTGAATATT TAAAAATAAAAATTATTTAGTCGCGAAAAAAA TAAAAAGAGACTTAAACAATTAGAAAGGCGTCACTCAGAGGAGTGAGAAAAAAA AAGACAGAGAAAGGTCGGTGGGTCGAGGCGATCGACCCCACTGCACCGCCTTTATCCTCGCCGCCGCAGTTCGAGTGCAACGCGTCCAAGATAACCGTAAATATTCCACCCCTCCCCCA $\rightarrow \operatorname{angan} 3$

AACCCCAACCATCCCCCTGGCTGCGCTCTCTACGACCCCCACGATGTCTCGGGCAGTCGGGTCGCACGCCGCTGCCCGGGGCGTGGTGGGGGCATCACACACACACCCACACCCACGTA

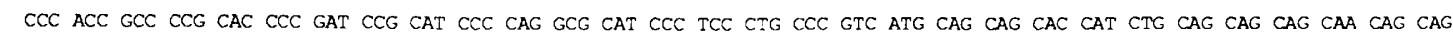
Met Gln Gln His His Leu Gln Gln Gln Gin Gln Gin

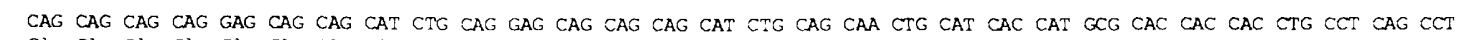
Gln Gln Gin Gln Glu Gln Gln His Leu Gln Glu Gln Gin Gln His Leu Gin Gin leu His His His ala His His His Leu Pro Gin Pro CTC CAC ACC ACC AGC CAT CAC CAC AGC GCG CAT CCC CAC CTG CAG CAG CAG CAA CAG CAG CAG CAA CAT COA 5

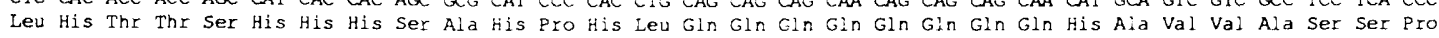
TCG GTG CTC CAG CAG CAG CAA CAG CAG TCA ACT CCC ACC ACA CAT TCC ACG CCC ACG CAT GCG GTT ATG TAC GAG GAT CCT CCG CCT GTG Ser val Leu Gln Gln Gln Gln Gln Gln Ser Thr Pro Thr Thr His Ser Thr Pro Thr His ala Val Met Tyr Glu Asp Pro pro Pro Val

011 CCA CTT GTC GCC GTG CAG CAG CAA CAC CTC CCC GCT CCG CAG CAG CAG CAG CAA CTC CAA CAG CAG CAG CAA CAG CAG CAA CAA CAG CTG

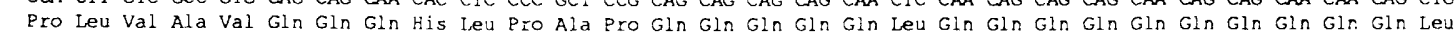

101 GCG ACA ACA CCG GTG GCC GGC GCC CTC AGT CCC GCC CAA ACA CCC ACT GGA CCT TCC GCC CAA CAA CAG CAA CAT CTC ACA TCG CCC CAC Ala Thr Thr Pro Val Ala Gly Ala leu Ser Pro Ala Gin Thr pro Thr Gly Pro Ser Ala Gin Gin Gin Gin His Leu Thr Ser Pro tiis

91 CAC CAG CAA CTG CCG CAG CAA CAA ACC CCG AAC AGT GTG CCA GTG CGC T̃C TCG AAT CTC CAG CAG CAG CAG CAA CAG CAG NAT GCT GCA His Gln Gln Leu pro Gln Gin Gin thr pro Asn Ser val Pro val Arg Ser Ser Asn Leu gin Gin Gln Gin Gin Gin Gin Asn Ala Ala EXON 1 EXON 5

281 GTT GCT CCT GGC CAG ACG CAG ATC GTT GCG CCG ACC ACG GCG AG: GT? TCT CCC TCC AGT GTT AGT TCT CAG AAG GAA GAC ATC AAT ATC 3 Val Ala Pro Gly Gln The Gln Ile Vai Aia Pro Thr Thr Ala Ser vai Ser Pro Ser Ser val Ser Ser Gin Lys Glu Asp ile Asn Met

371 TCC ATC CAA TTA GCG CCA CTG CAT ATA CCC GCC ATC CSG GCC GGT CCG GGA TTC GAG ACG GAC ACC TCG GCG GCG GTC AAG CGC CAC ACG Ser Ile glr Leu Ala pro leu His ile Pro Ala Ile Arg Ala Gly Pro Giy phe Glu thr Asp Thr Ser Ala Ala Val Lys Arg His Thr

GCA CAC TGG GCC TAC AAC GAC GAG GGA TTC AAT CAG CAT TAC GGC TCO GGG TAC TAC GAC CGC AaG CAC ATG TTC GCC TAT CCT TAC CCA Ala his Trp Ala Tyr Asn Asp Glu Gly ghe Asn Gln His Tyr Gly Ser Gly Tyr Tyr Asp are Iys His Met Phe Ala Tyr Pre Iyr Pro EXON $5+$ EXON 6

1551 GAA ACG CAG TTT CCG GTT GGT CAG TAC TGG GGC CCC AAC TAC CGC CCC GAT CAG ACC ACC TCT GCC GCA GCG GCG GCG GCC TAC ATG AAC

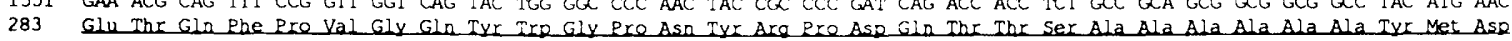

1641 GAG GCG GAG CGC CAC GTG ACC GCC GCC GCG CGA CAG TCC GTC GAG GGC ACA TCG ACG TCC AGC TAC GAG CCG CCC ACC TAC TCC TCG CCA

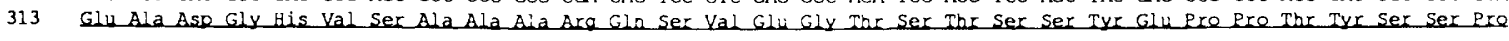
1731 GGC GGC CTG CGC GGC TAT CCC ACC GXC AAC 6 i ENAC 7

TCC AGC TCA GGA GCC TCT GGT GGA TTA TCC GTG GGA GCA GTG GGT CCT TGC ACG CCC 343 Gly Gly Lell Aro Gly Tyr Pre Ser Glu Asn. Tyr Ser Ser Ser Gly Ala Ser Giy Giy Lell Ser Val Gly Ala Val Gly Pro Cys Ihr Pro

1821 AAT CCC GGA CTG CAC GAG TGG ACC GGT CAG GTG TCC GTC CGG AAA AAG CGS AAG CCG TAC TCC AAG TTC CAG ACC CTG GAG CTG GAG AAG

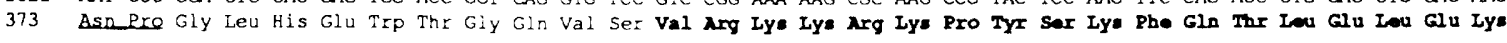
EXON $7 \quad \downarrow \quad$ EXON 8

1911 GAG TTT CTT TTC AAT GCG TAT GTT TCC AAG CAA AAG CTT MGG CAA TmG GCC AGA AAT TTG CAG CTG ACC GAG CGA CAG GTC AAG ATA TGC

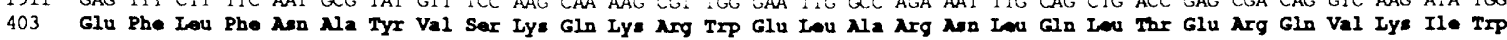

2001 TTC CAG AAT CGG CGC ATG AAG AAC AAG AAG AAC TCA CAG CGC CAG GCC AAT CAG CAG AAC AAC AAC AAC AAT TCG AGC AGC AAC CAC AAC

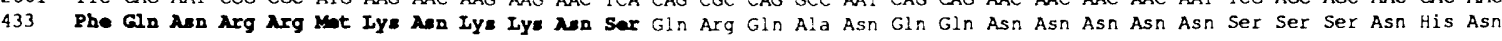

2091 CAC GCG CAG GCG ACC CAG CAG CAC CAC AGC GGC CAC CAC CTG AAC CTT AGC CTG AAC ATG GGT CAC CAT GCC GCC AAG ATG CAC CAG TGA 463 His Ala Gln Ala Thr Gin Gln His His Ser Giy His His Leu Asn Leu Ser Leu Asn Met Gly his His Ala Ala Lys Met His Gln STOP

2181 CCCTTGGACAACAGCCAGGCCTGGGCCATGGCTTTGCCACCTACTAGCAGTTAGCCAATCCGAGTTCGGGTAACCCCAGCTCGAATCCCAACCCCATGTCCGATCCGAATCACCATCAT CTATACAAGAACGAGCTGGCCATGGACTTTCCATGCTAGTCCAGCGATTGGAAGGGCGATTCCAGCCAGGCCGAGTTCAGTCGGTTAAATGTACAAAAACCAGAGATCTCTAGCATGCG GGATAGGAATATGTGACCACAATGAGGAGCAAGGATGTGGATGAGCAACTGCCCAGAAGTGCGCAGGCGTCGCTGATGTGTGACCAACCGACGTTGATGGAAATCCAGTTTATTATTAA GTCAGTTCTACGGATCCCAGAGATCCAAGCCCCAACACGATAATGCAGCTTAGTTCGGTAGTTGAATATAGATACGAGTAAGATGAAGAGTAAGCAGCAGCAGTAGCAGATGCACTTGA AATTCGCAACTGTACGAAAATATATGTATGTACGTATTTCTCTCAACGCTCTCATTAGCCTAGGCGAGCACTATGAATTTTCCGAACTATAAATTATGAATATGAATATACTTAAACGI CAGTGAATATAACCCCGCATAAATTATGAATACACGCGTTCGAGTAGTAGATTTTACCATACCTATCCAATTAAGAGCGGCCACAAGGCGGCTGAGTTAGGCTGAGCAGCAGAACACAT CAGTGAATATAACCCCGCATAAATTATGAATACACGCGTTCGAGTAGTAGATTTTACCATACC ATCCAATTAAGAGCGGCCACAAGGCGGTGAGTTAGGCTGAGCAGCAGALCACAT

3014 AATGTTCGTCGTGTCGTGTCCTTTGATACCTTCTAAGTTCCTGTATATAAACTAAGACATTGCGCTGATTTCCGGCCGAAGCGAGCACTCGATAACTAAATTACATCAGATATATGTAT ATGTATATTGCGTACACGCAGAGATATTCAATATTTGTATAATATGAACTCGGATTCGATTTTAGCAAATGGTTAATTGTAAGTTGCAAAAATTTCAATGAGTGTGTGCATGTTTACCC

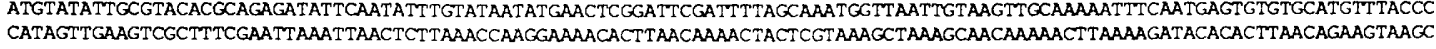
CATAGTTGAAGTCGCTTTCGAATTAAATTAACTCTTAAACCAAGGAAAACACTTAACAAAACTACTCGTAAAGCTAAAGCAACAAAAACTTAAAAGATACACACTTAACAGAAGTAAGC ATGTGTATCGACGCCGCTTGATCCTGATATTAAGTCTAAGTTTAGTTGTGTTGTGTAATTATCGATTTGTTAATGTTTTGCCCCGAGCATTATATTATATTATGCTAACCTATACCTAT ACCTACACCTACACCTATGCCTATCATTATATGTGTATAATTAGCCTATACATACTTGATGAAGAAATGATTTCACCCACTGCTTTATTCATGTTCTTGTATTATTATTATTTCGAGCC CTCGATAAGTTGTAGTCTAAAGTCGGTTATGTTTATGATTATGTTCGATTATAGTTTGTTTAGTGAATTTTAATCTAGCGTTAGCAATTCTCTTTTTTAAAAAGTTAATTATTGTGMA

3847 MATACAACAAGTTGCAGAACTGCAAAAATATACACACAAAAAAAAAAAAAAAAA 3902 bp

Figure 2. DNA sequence and predicted amino acid sequence of $A b d-B$ cDNAs 3 and 5 and genomic sequences upstream of cDNA 3 . The limits of all exons and cDNAs are marked by arrowheads. The homeo domain is shown in boldface type. The prospective polyadenylation signal is indicated (nucleotide 3844 to 3849; AATAAA). The underlined sequence corresponds to the NciI DNA fragment used to construct a $\operatorname{trp} E / A b d-B$ fusion gene and protein.

rich, containing two regions (amino acids $2-30$ and $108-131$, inclusive) predominantly (20 of 27 and 18 of 24) glutamine, in addition to interspersed small runs (4-8 amino acids) of glutamines (amino acids: 57-64, 76-81, 153-156, and 183-189, inclusive). These sequences correspond to the previously described $M$ or opa repeats that are found in several hundred locations in the Drosophila genome (Wharton et al. 1985).

As reported previously (Regulski et al. 1985) $A b d-B$ proteins contain a homeo domain. Our sequence data place this homeo domain near the carboxy-terminal end (amino acids $386-445$ ) of the $A b d-B$ proteins. The 
Table 1. Abd-B donor and acceptor splice-site sequences

\begin{tabular}{|c|c|c|c|}
\hline Exon splice & cDNA position & $\frac{\text { Donor sequence }}{{ }_{\mathrm{A}}^{\mathrm{AG} / G T_{G}^{\mathrm{A}} \mathrm{AGT}^{2}}}$ & $\frac{\text { Acceptor sequence }}{{ }_{\mathrm{CC}}^{\mathrm{T}} \mathrm{N}_{\mathrm{T}}^{\mathrm{C}} \mathrm{AG} / \mathrm{A}^{\mathrm{a}}}$ \\
\hline $4-5$ & 1359 & AAG/GTGAGG & TTTCAG/A \\
\hline $5-6$ & 1571 & GGT/GTAAGT & $\mathrm{CCGCAG/C}$ \\
\hline $6-7$ & 1773 & CAG/GTGAGT & TT TCAG/G \\
\hline $7-8$ & 1988 & CAG/GTGAGT & TT TCAG/G \\
\hline
\end{tabular}

a Consensus-derived donor and acceptor sequences (Mount 1980).

$A b d-B$ homeo domain is no more than $55 \%$ identical with any found in Drosophila. As a consequence, it has been placed in a separate class by Scott et al. (1988). The homeo domain is predicted to contain three helixes (Laughon and Scott 1984). The first two helixes of $A b d-B$ show poor homology with those of other BX-C genes. The third helix of $A b d-B$ (amino acids 425-436, inclusive, Fig. 2), the putative DNA-binding domain (Laughon and Scott 1984), however, differs from that of $U b x$ and $a b d-A$ only by substitution at position 429 (Fig. 2) of isoleucine for valine.

\section{Expression of Abd-B sequences in Escherichia coli}

To identify and localize the $A b d-B$ protein products we generated $A b d-B$-specific monoclonal antibodies. We cloned a 312-bp Ncil restriction fragment from cDNA 5 (underlined sequence shown in Fig. 2) into an E. coli expression vector containing the $\operatorname{tr} E E$ gene (Spindler et al. 1984). The NciI fragment encodes an hydrophilic region of the putative $A b d-B$ protein. Furthermore this fragment contains neither the homeo box nor any of the highly repetitive amino acid runs. The fusion protein was partially gel-purified and injected into mice to develop monoclonal antibodies. Three monoclonal antibodies were found to be specific for $A b d-B$ : one, 1A2E9, has been used for most of our studies. Its specificity for the $A b d-B$ portion of the fusion protein is shown in Figure 4.

\section{Abd-B nuclear embryonic proteins}

Because developmental Northern analysis (Fig. 3; Kuziora and McGinnis 1988; Sanchez-Herrero and Crosby 1988) shows that the $A b d-B$ transcripts are abundant during embryogenesis and because the presence of a homeo box suggests a nuclear localization, we used embryonic nuclear extracts prepared by the method of $\mathrm{He}$ berlein and Tjian (1988) to identify $A b d-B$ proteins. The extracts were subjected to one-dimensional, sodium dodecyl sulfate (SDS) gel electrophoresis and transferred electrophoretically to nitrocellulose. Specific proteins were identified by immunochemistry. The 1A2E9 antibody consistently detects two proteins of $M_{r} 54$ and 36 $\mathrm{kD}$ (Fig. 5E). The sizes of the observed protein products are consistent with the coding capacity of the $A b d-B$ transcripts. The extracts also were subjected to a two-dimensional analysis. In the first dimension we employed a nonequilibrium pH-gradient gel because of the predicted basic nature of the proteins. In the second dimension we employed an SDS-polyacrylamide gel. At each relative mobility, we resolved families of proteins with subtly different molecular weights and isoelectric points (Fig. 6). The observed isoelectric points of the $A b d-B$

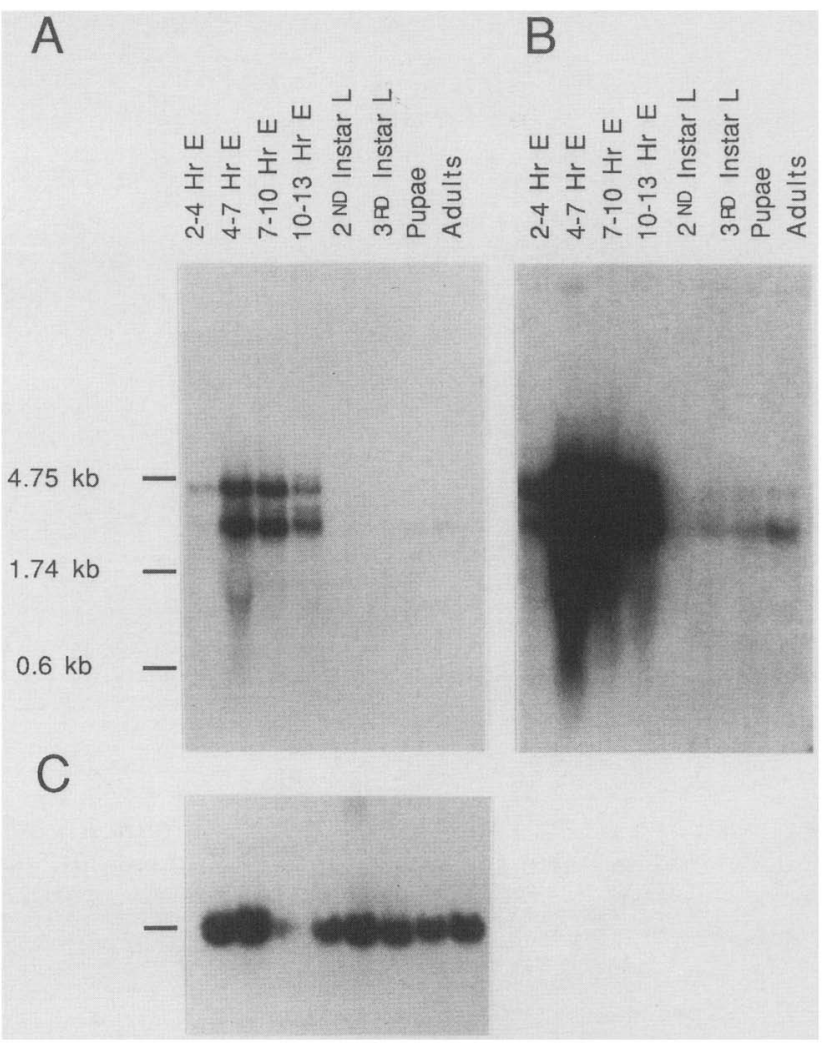

Figure 3. Developmental expression of $A b d-B$ RNAs. Ten micrograms of poly $(A)^{+}$RNA isolated from different developmental stages were electrophoresed on a $1 \%$ formaldehydeagarose gel and transferred electrophoretically to a nylon membrane filter. (A) The filter-bound RNA was hybridized with a uniformly labeled probe synthesized from a $1.2-\mathrm{kb}, 3^{\prime}$ fragment of cDivA 5 (see text). The four transcripts detected at this exposure, $4.7,4.3,3.7$, and $3.3 \mathrm{~kb}$ in length are indicated by the arrows. $(B)$ The same filter shown in A exposed $5 \times$ longer. The 7.8 -kb transcript weakly detectable in $4-$ to $7-\mathrm{hr}$ and $7-$ to $10-\mathrm{hr}$ embryos is indicated by the arrow. $(C)$ The same filter shown in $A$, washed and rehybridized with a nick-translated, ribosomal protein clone (RP49). 


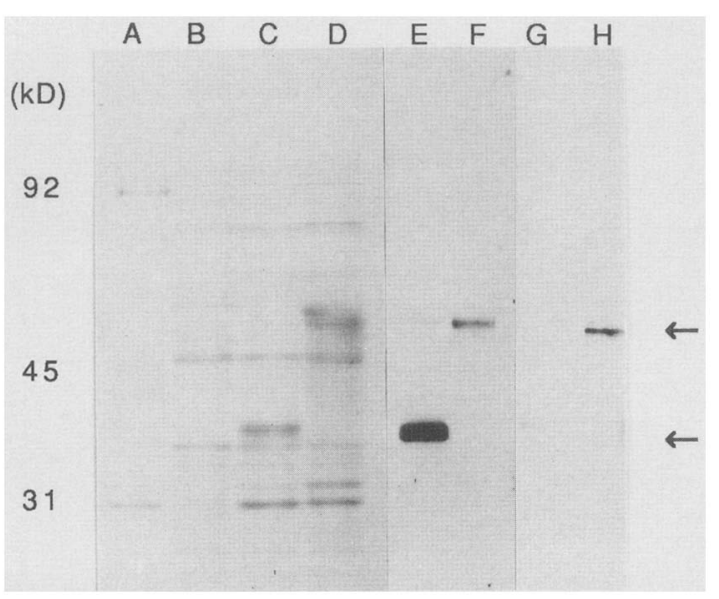

Figure 4. $\operatorname{trp} E / A b d-B$ fusion proteins and monoclonal antibody specificity. (Lane $A$ ) Molecular weight standards. (Lanes $B-D$ ) Whole-cell lysates were prepared from untransformed and transformed MC1061 E. coli cultures, separated by discontinuous, SDS, $12 \%$ polyacrylamide-gel electrophoresis and stained with Coomassie blue. (Lane B) Untransformed MC1061 proteins. (Lane C) MCl061 cells transformed with pATH 1 vector, without an insert, which expresses a $37-\mathrm{kD}$ partial trpE protein indicated by the lower arrowhead. (Lane D/ MC1061 cells transformed with plAbd-B, which expresses a $47-\mathrm{kD}$ fusion protein indicated by the upper arrowhead. (Lanes $E-H$ ) Whole-cell lysates, prepared from MC1061 transformed with pATH 1 (lanes $E$ and $G$ ) or plAbd-B (lanes $F$ and $H$ ), were electrophoresed and transferred electrophoretically to nitrocellulose filters and assayed for antibody specificity. (Lanes $E$ and $F$ ) The nitrocellulose filter was incubated with an antibody $|3 \mathrm{~F} 9|$ that recognizes the $\operatorname{trp} E$ protein. (Lanes $G$ and $H$ ) The nitrocellulose filter was incubated with a monoclonal antibody (1 A2E9) that recognizes only the $A b d-B$ portion of the fusion protein. The second antibody in all cases was alkaline phosphatase-conjugated, goat anti-mouse immunoglobulin.

proteins are more acidic than the predicted ones (data not shown). Both the fushi tarazu (ftz) and engrailed (en) homeo proteins have been reported to be phosphorylated at threonine and serine residues (Gay et al. 1988; Krause et al. 1988). Presumably, the $A b d-B$ proteins are phosphorylated also so that the observed charge differences among the $A b d-B$ proteins may reflect different degrees of phosphorylation.

As a control to determine the quality of our extracts, $U b x$ proteins were visualized using a $U b x$ antibody (FP3.38). Our extracts contained only the intact $U b x$ proteins all of which are known to cluster from 41 to 45 $\mathrm{kD}$ (Gavis and Hogness, pers. comm.) and no lower molecular weight $U b x$ degradation products (Fig. 5D).

\section{Embryonic localization of Abd-B proteins}

We used horseradish-peroxidase labeling to detect the segmental distribution of $A b d-B$ proteins in whole mounts of embryos (Fig. 7) and in dissected embryonic nervous systems (Fig. 8). Although $A b d-B$ transcripts are detected by the stage of cellular blastoderm, we do not

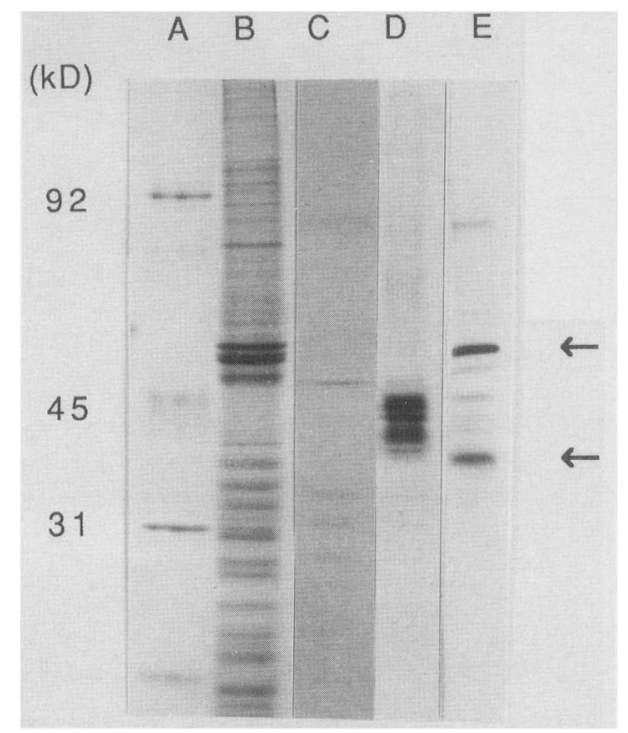

Figure 5. Identification of $A b d \cdot B$ protein products in embryonic nuclear extracts. (Lane $A$ ) Molecular weight protein markers. (Lane $B$ ) Total nuclear proteins from 4- to 24 -hr embryos were electrophoresed on a discontinuous, $12 \%$ polyacrylamide gel, and stained with Coomassie blue. (Lanes $C-E$ ) The same nuclear protein preparation shown in (lane $B$ ) was electrophoresed and transferred electrophoretically to nitrocellulose for immunoblotting. (Lane $C$ ) Control nitrocellulose panel incubated with secondary antibody alone. (Lane $D \mid$ Nitrocellulose panel incubated with $U b x$ monoclonal antibody (FP3.38). The antibody binds to at least six proteins of $M_{\mathrm{r}} 37-45 \mathrm{kD}$. (Lane $E$ ) Nitrocellulose panel incubated with $A b d-B$ monoclonal antibody (1A2E9). The antibody binds to two groups of proteins at $M_{\mathrm{r}} 54$ and $36 \mathrm{kD}$.

detect any $A b d-B$ protein expression above background prior to germ-band extension; that is, mid to late stage 8 embryos (as defined by Campos-Ortega and Hartenstein 1985). Abd-B proteins are visible first in a band of ectodermal cells at the posterior tip of the extended germ band as well as in cells of the proctodeal primordium (Fig. 7A). The band of ectodermal cells derive from PS 13 and PS 14 as determined by double-labeling with an en antibody (data not shown). By the time germ-band extension is completed, in a lateral view, we see labeling of the posterior ectoderm and mesoderm in PS 13 to PS 15, inclusive, and in the mesoderm, including the cells surrounding the tracheal pits, but not in the ectoderm of PS 11 and PS 12 (Fig. 7B and H). In a dorsal view of an embryo at germ-band extension, the posterior border of $A b d-B$ labeling does not include the proctodeal opening and the labeling in PS 12 is in a row of cells that borders the neurogenic region (Fig. $7 \mathrm{C}$ ). At germ-band extension, the Malpighian tubules start to grow out of two diverticula of the hindgut. These cells are labeled and can be seen in a dorsal view though at a different plane than that shown in Figure 7C. During germ-band retraction when the posterior spiracles form, we see labeling of the nuclei in a subset of cells in the sixth, seventh, and 
eighth abdominal segments including the cells surrounding the posterior spiracles (Fig. 7D). At germ-band retraction, in a ventral view, we detect strong labeling at the posterior end of the developing central nervous system $(\mathrm{CNS})$. $A b d-B$ expression is most abundant in the last neuromere, PS 14; diminishes in PS 12 and PS 13 and further tapers off more anteriorly (Fig. 7E, F, and I). In a dorsal view, a subset of cells of the visceral mesoderm surrounding the hindgut are labeled (Fig. $7 \mathrm{~F}$ and G). Also, we detect label in a subset of cells of the Malpighian tubules (data not shown). Double-labeling with DAPI and rhodamine-conjugated secondary antibodies reveals that the staining is nuclear (data not shown).

As a positive control for these experiments, wild-type embryos were stained with $U b x$ antibodies (Fig. 7J). $U b x$ expression, as reported previously (White and Wilcox 1984; Beachy et al. 1985), is first seen in PS 5, peaks in PS 6, and then tapers off but is still detectable in PS 7-PS 12.

Also, we investigated the distribution of $A b d-B$ proteins in homozygous $P c$ embryos. These animals die in late embryogenesis, and the morphology suggests that most of the body segments are transformed towards the eighth abdominal segment (PS 13). At germ-band extension in homozygous $P c$ embryos we detect $A b d-B$ expression commencing weakly in PS 5, extending at moderate levels from PS 6 to PS 12 and at nearly normal levels in PS 13 and PS 14. A dorsal view of the expression in PS 9 to PS 14 is shown in Figure 7K. By germband extension, $A b d-B$ expression can be detected in all the neuromeres of the CNS and in the ectoderm of all the segments (Fig. 7L).

Although labeling with 1A2E9 is seen in the CNS, the mesoderm and the epidermis, the most prominently labeled structure in embryos is the CNS. For this reason we dissected the CNS of wild-type and mutant embryos to determine more accurately the limits of $A b d-B$ expression. As expected, 1A2E9 is localized to neuromeres 10 to 14, inclusive, (posterior fourth abdominal to anterior ninth abdominal segments, inclusive) of the CNS (Fig. 8A). The labeling pattern is complex. There is a gradient of expression, weakly detectable in the tenth neuromere which becomes more intense in each more posterior neuromere with the highest expression in the most posterior neuromere, neuromere 14 . The expression, in each neuromere, has at least two components: (1) it is bilaterally symmetric as was observed for $U b x$ (White and Wilcox 1984; Beachy et al. 1985), and (2) the nuclei in the anterior portion of each neuromere are labeled more intensely than those in the posterior portion resulting in a striped appearance.

Embryos deficient for the distal end of the complex ( $D f P 9 / D f C 4$ ) including all of the $A b d-B$ domain provide a negative control. They are identifiable because they have an extra segment and were found to have only background levels of antibody staining (Fig. 8B). Thus, the lack of antigen in $A b d-B^{-}$embryos shows that the 1A2E9 antibody is specific for the $A b d-B$ proteins and confirms that the ORF we identified corresponds to that of the $A b d-B$ proteins.

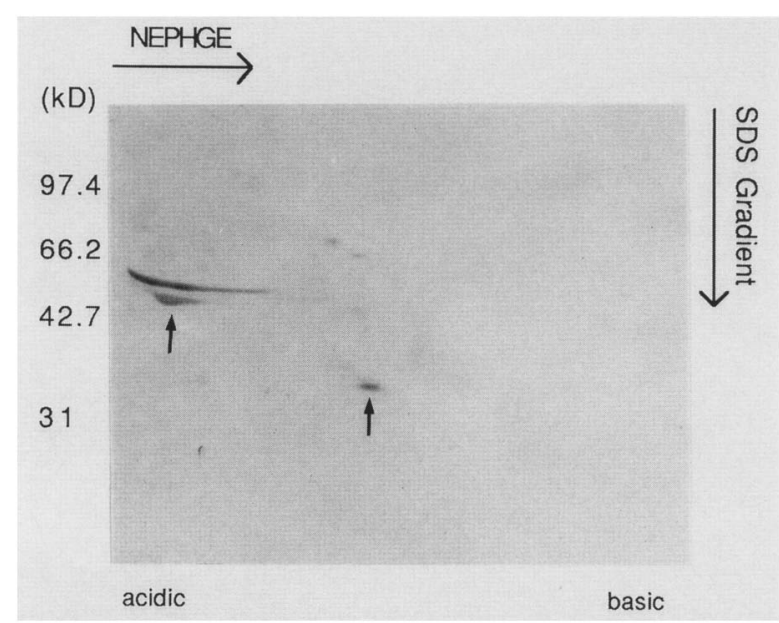

Figure 6. Distribution of embryonic nuclear $A b d-B$ protein products as a function of molecular weight and relative isoelectric point. Total nuclear proteins from 4- to 24 -hr embryos were electrophoresed in the first dimension by NEPHGE with a gradient of $\mathrm{pH} 6-10$, and in the second dimension by a gradient of acrylamide from 5 to $15 \%$. The proteins were transferred electrophoretically to nitrocellulose and incubated with $A b d-B$ monoclonal antibody. The large arrows indicate the direction of electrophoresis, whereas the small arrows identify two sets of protein products. Size standards are indicated on the left.

\section{Discussion}

\section{Genomic organization}

Among the homeotic genes that have been characterized, the genomic organization of the $A b d-B$ domain is one of the most complex. It spans some $100 \mathrm{~kb}$, contains at least eight exons, and produces five major transcripts that differ in structure as well as in their molecular lengths $(7.8,4.7,4.3,3.7$, and $3.3 \mathrm{~kb})$ (Kuziora and McGinnis 1988; Sanchez-Herrero and Crosby 1988, this paper). We presume that the $7.8-\mathrm{kb}$ transcript arises from a distal promoter $(\mathrm{P} 1)$, the $3-\mathrm{kb}$ transcripts from an internal promoter $(\mathrm{P} 2)$, and the $4-\mathrm{kb}$ transcripts from the most proximal promoter (P3) (Fig. 9). The $A b d-B$ transcription units are contained within a $45-\mathrm{kb}$ region. On the basis of genetic data, the remaining $50 \mathrm{~kb}$ that lie $3^{\prime}$ to the transcription units and correspond to $i a b-5, i a b-6$, and $i a b-7$, seem to be required for proper spatial expression of the P3 transcripts (Duncan 1987).

Transcripts from the $\mathrm{P} 1$ and $\mathrm{P} 2$ promoters contain a coding region that produces a $30-\mathrm{kD}$ homeo protein for a $36-\mathrm{kD}$, if the protein is initiated at a GUG as proposed by Delorenzi et al. 1988), whereas transcripts from the P3 promoter contain a coding region that produces a $54-\mathrm{kD}$ homeo protein. The predicted small homeo protein, whether $30 \mathrm{kD}$ or $36 \mathrm{kD}$, lacks 221 amino acids. This stretch of amino acids forms the amino-terminal end of the $54-\mathrm{kD}$ homeo protein and includes multiple copies of the $M$ repeat.

Akam et al. (1988) suggested that the ancient ancestor 

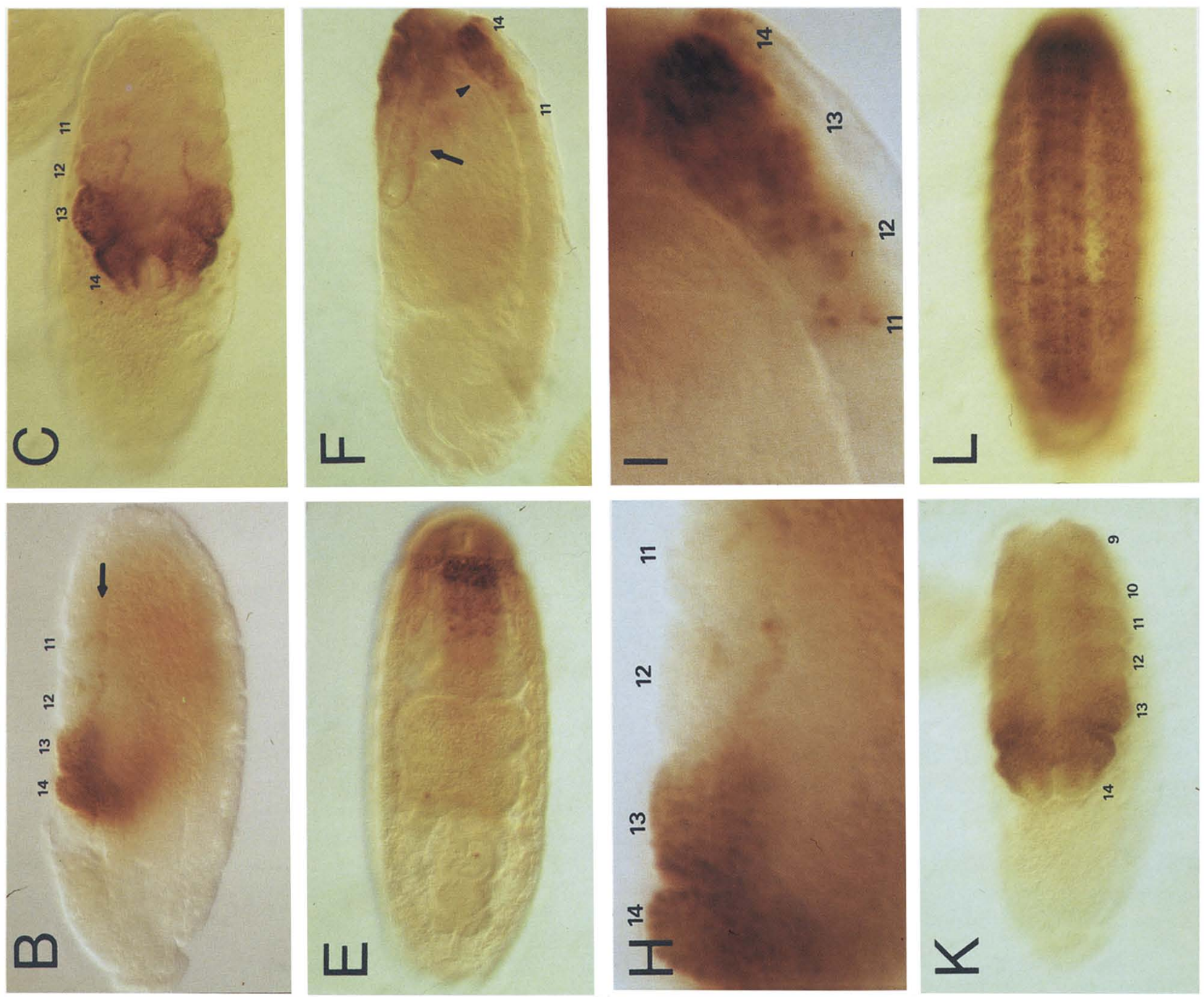

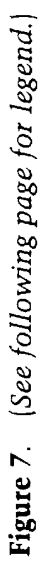
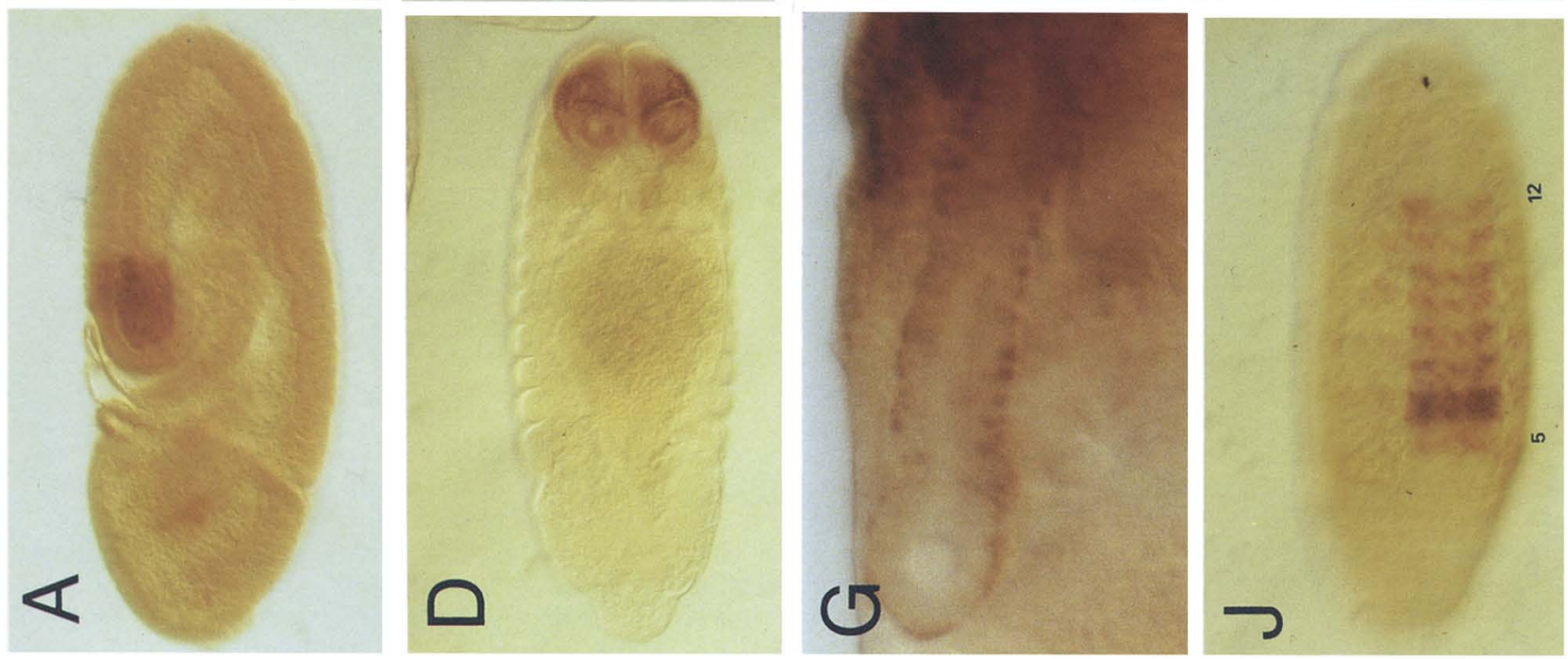
of the myriapod-insect lineage contained a labial-like and an $A b d-B$-like homeotic gene. We find that $A b d-B$ has a splice site in the recognition helix that is in exactly the same position as the splice site in the labial recognition helix. This identity of splice sites suggests that the labial and $A b d-B$ homeo domains derive from a common ancestral homeo domain that may have predated the myriapod-insect lineage.

\section{Abd-B protein expression}

Embryos that are homozygously deficient for the $A b d-B$ domain $(D f$-C4/Df $P 9)$ have PS 10 to PS 15 , inclusive, transformed toward more anterior parasegments. Presumably this phenotype results from the absence of $A b d-B$ expression. Therefore, in wild type we would expect to see $A b d-B$ expression throughout these six parasegments. First, we detect $A b d \cdot B$ expression in PS 13 and PS 14 of early germ-band-extended animals. By the time the intersegmental grooves form, we see ectodermal and mesodermal tissues of PS 13 to PS 15 labeling, as well as mesodermal labeling of the more anterior parasegments PS 11 and PS 12. Only in the CNS of germ-band-retracted embryos do we see labeling of PS 10. Late in embryogenesis we detect labeling of the visceral mesoderm surrounding the hindgut and in two of the four Malpighian tubules. The gene caudal, which lies outside the BX-C in chromosome 2 and is expressed in more posterior structures of the embryo than is $A b d-B$, also is reported to be expressed in the Malpighian tubules (MacDonald and Struhl 1986). It will be interesting to see if the expression of these two homeo domain proteins is mutually exclusive with respect to these tubules.

With our $A b d-B$ antibody, 1A2E9, we detect two embryonic nuclear proteins, $54 \mathrm{kD}$ and $36 \mathrm{kD}$ in size. Be- cause the 4-kb $A b d-B$ transcripts are primarily restricted spatially to PS $10-13$ (with possibly lower expression in PS 14 and PS 15) and the 7.8- and 3-kb $A b d-B$ transcripts are restricted spatially to PS 14 and PS 15 (Kuziora and McGinnis 1988; Sanchez-Herrero and Crosby 1988), we expect that the $54-\mathrm{kD}$ and the $36 \mathrm{kD} A b d \cdot B$ proteins will be correspondingly restricted spatially. Our antibody detects only the sum of the distribution of both proteins since it recognizes an epitope common to both proteins. To address the issue of spatial distribution of these proteins directly would require the development of antibodies specific to each. However, we can determine whether the two proteins are differentially expressed by studying various mutants that affect development of the posterior abdominal region. Thus, we expect strong iab-8 mutants, such as 1065 (Fig. 9) that disrupt the P1 and $\mathrm{P} 2$ promoters, to be unable to make the $36-\mathrm{kD}$ protein but still retain the ability to make the $54-\mathrm{kD}$ protein. We would expect certain iab-7 mutants, such as D14 (Fig. 9), to be unable to make the $54-\mathrm{kD}$ protein but retain the ability to make the $36-\mathrm{kD}$ protein. Currently, we are testing these predictions using the 1A2E9 antibody.

\section{The role of $\mathrm{Abd}-\mathrm{B}$ in gene regulation}

Proteins with homeo domains of the $A b d-B$ type presumably exert a master regulatory function by binding to specific DNA motifs in other genes thereby activating or repressing the transcription of such genes; thus, the homeo-domain-containing protein $U b x$ has been shown to mediate its regulatory effects by binding to a DNA motif composed of a fivefold tandemly repeated TAA (Beachy et al. 1988). Although the homeo domains of $U b x$ and $A b d-B$ have diverged considerably in the first and second helices, they differ as already noted in only

Figure 7. Expression of $A b d-B$ proteins in embryos. Embryos were dechorionated, the vitelline membrane removed, fixed, and incubated with $A b d-B$ antibody (1A2E9) and proteins were visualized by use of horseradish-peroxidase-conjugated secondary antibodies. The anterior end of the embryos is always to the left. $(A, B, F, G, H$, and $I)$ Lateral views; $(C, D$, and $K)$ dorsal views; and $(E$, $I$, and $L)$ ventral views of optical sections using Nomarski optics. (A) An embryo that has completed the fast period of germ-band elongation (late stage 8 ). $A b d-B$ is expressed in a band of $12-17$ ectodermal cells starting at the tip of the extended germ band. It is expressed weakly in the proctodeal primordium but not the posterior midgut primordium. (B) A fully extended germ-band embryo (stage 12). Strong ectodermal and mesodermal $A b d-B$ expression in PS 13, PS 14, and PS 15, with only mesodermal expression in PS 11 and PS 12 is indicated by the arrow. (C) Dorsal view of an embryo the same age as that shown in $B$. Labeling is seen in the ectoderm of PS 13 , PS 14, and PS 15. The posterior border of the label corresponds to cells surrounding the proctodeal opening. The heaviest labeling occurs in the epidermal groove between PS 13 and PS 14. (D) Dorsal view of an embryo in the fast period of germ-band shortening (late stage 12). The tip of the retracting germ band is at about $20 \%$ egg length $\{E L)$. Strong $A b d-B$ expression is detected in cells surrounding the differentiating posterior spiracles, and lesser $A b d-B$ expression is seen more anteriorly. $(E)$ Ventral view of an embryo that has completed germ-band shortening (stage 14). Strong $A b d-B$ expression is detected in neuromere 14 of the developing CNS with a moderate level of expression detected in neuromeres 11 to 13 . $(F)$ Lateral view of an embryo the same age as that shown in $E$. Strong $A b d-B$ expression is seen in the dorsal epidermis, the posterior spiracles, the posterior neuromeres of the developing CNS, and the visceral mesoderm surrounding the hindgut; no expression is detectable in the anal pads. $(G)$ Higher magnification of the visceral mesoderm surrounding the hindgut of the embryo in $F$. $A b d-B$ is expressed in lines of cells outside the hindgut. $(H)$ Higher magnification of PS 11 to PS 14, inclusive, of the embryo shown in $B$. The tracheal pits of PS 11 and PS 12 as well as the mesoderm are stained weakly. (I) Higher magnification of neuromeres $11-14$ shown in $F$. (J) Ventral view of a wild-type embryo (stage 14) labeled with $U b x$ antibody (FP 3.38). Nuclei of the CNS are labeled clearly in neuromeres $5-12$ with the peak in neuromere 6 . $(K)$ Dorsal view of a $P c^{3} P 5$ homozygous embryo (stage 12), the same age and view as the wild-type embryo shown in $(C)$. The level of expression of $A b d-B$ in PS 13 and PS 14 appears normal, whereas expression in PS 9-PS 12 inclusive, is elevated uniformly. $(L)$ Ventral view of a $P C^{3} P 5$ homozygous embryo (stage 14), the same age and view as the wild-type embryo shown in $E$. $A b d$-B proteins are expressed in all neuromeres of the developing CNS. The highest level of expression is in the most posterior neuromere, with the more anterior neuromeres showing an intermediate level of expression. 


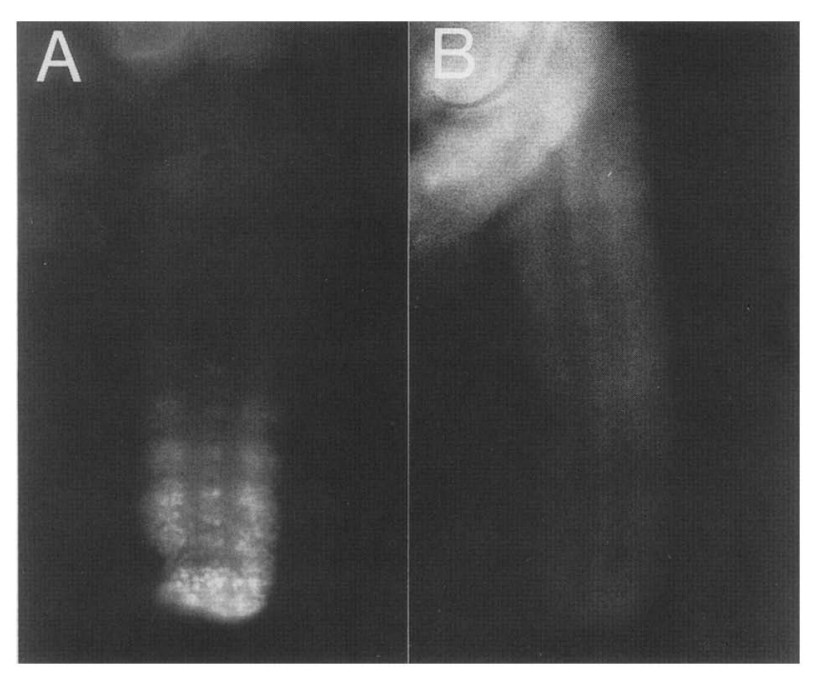

Figure 8. Localization of $A b d-B$ proteins in the CNS of wildtype and $A b d-B^{-}$embryos. (A) CNS dissected from a wild-type embryo (stage 14) incubated with $A b d-B$ antibody (1A2E9) followed by FITC-conjugated, goat anti-mouse immunoglobulin, photographed by fluorescence microscopy. Labeling can be detected weakly in the 10th neuromere, increasing in intensity posteriorly with the most intense labeling in the 14th neuromere. $(B)$ Dissected CNS is shown from an $A b d-B^{-}(D f C 4 / D f$ $P 9 \mid$ embryo labeled and photographed as in $A$. No labeling is detected above background.

one amino acid in the third, or recognition, helix. It is not clear whether $A b d-B$ would bind to a different motif from that of $U b x$ or whether they would both bind to the same motif but with different affinities. Outside of the homeo domain we have not been able to detect significant sequence homologies using dot-matrix analyses. However, $U b x$ and $A b d-B$ both contain stretches of repeated amino acids, glycine and glutamine, respectively, in roughly the same relative position to the homeo domain.

We anticipate that the $A b d-B$ proteins will be involved in regulating two classes of genes in addition to the possibility that they are autoregulatory. One class would be other homeo-box-containing genes such as $U b x$ and Antp whose expression has been shown to be altered in animals lacking the $A b d-B$ domain (Struhl and White 1985; Casanova and White 1987; Duncan 1988). The second class would be a specific set of downstream genes that are required for the formation of structures unique to the posterior segments.

\section{Trans-regulation of Abd-B by polycomb}

$\mathrm{PC}^{+}$acts as a negative trans-regulator of the genes of the BX-C. Embryos homozygous for the $P_{C}$ mutation show a transformation of most of the body segments toward A8 (Lewis 1978). In germ-band-extended embryos that are homozygous for $P c^{3}, A b d-B$ proteins begin to be expressed weakly in PS 5 and then at higher levels in PS 6 to PS 15, inclusive; this is in contrast to the $A b d-B$ transcript distribution, which is detected starting in PS 1 (Kuziora and McGinnis 1988). In germ-band-retracted embryos homozygous for $P c^{3}, A b d-B$ expression is highest in neuromere 14, and moderate in all of the more anterior neuromeres. Expression also is elevated in the epidermis of every segment. This pattern of $A b d-B$ expression in late $P c$ embryos is consistent with the $A b d-B$ transcript distribution previously reported for such animals (Kuziora and McGinnis 1988).

\section{Vertebrate Abd-B homologs}

The $A b d-B$ homeo domain is represented in vertebrates by well-conserved homologs. It is greater than $70 \%$ identical with murine homeo domains: Hox-1.7 (Rubin et al. 1987), Hox-3.2 (Breier et al. 1988), Hox-5.2 (Duboule and Dolle 1989) and a human homeo domain: $H O X 2.5$ (Boncinelli et al. 1988). Indeed, the $A b d-B$ homeo domain is more similar to such vertebrate domains than it is to any homeo domain in Drosophila, even those of the separate clusters, ANT-C and BX-C. Moreover, in the recognition helix of the homeo domain, the amino acid sequence of $A b d-B$, is identical with that of its murine and human homologs. Just as $A b d-B$ is expressed in the more posterior body segments of Drosophila so its homolog in the mouse is expressed in the more posterior somites of the spinal cord (Rubin et al. 1987). The colinearity of gene order in the chromosome and spatial expression along the antero-posterior (rostral-caudal) axis, first found in Drosophila, occurs in an even more remarkable fashion in mice (Gaunt et al. 1988) and in human beings (Boncinelli et al. 1988) where the ANT-C-like and the BX-C-like genes are united in a single cluster.

\section{Materials and methods}

Nucleic acids preparation and DNA sequence analysis

Isolation of genomic DNA from the distal end of the BX-C has been described previously by Karch et al. (1985). For our studies, we subcloned the EcoRI restriction fragments from +150 to +200 into pUC18. We described previously the isolation of cDNA 3 and cDNA 5 (Celniker and Lewis 1987). Additional cDNAs were obtained by screening an embryonic library (kindly provided by Kai Zinn) with purified genomic restriction fragments from +150 to +190 of the BX-C walk.

Genomic and cDNA sequences were generated according to Sanger et al. (1980) using ${ }^{35} \mathrm{~S}$ in place of ${ }^{32} \mathrm{P}$. Ambiguities or polymerase stops were resequenced according to Maxam and Gilbert (1980). Gel-purified genomic DNA fragments were cleaved with Sau3AI and cloned into the BamHI site of M13 double-stranded DNA. Only cDNA-cross-hybridizing genomic clones were sequenced. cDNA 5 was sequenced on both strands using convenient restriction sites and subcloning into either M13mp18 or M13mp19. cDNA 3 was sequenced as described for cDNA 5 but sequenced only on one strand. Dot-matrix analysis was performed with the DNA Inspector IIe (Textco).

\section{Construction of trpE hybrid gene fusion}

pATH l, a plasmid vector used for the construction of $\operatorname{trp} E$ hybrid gene fusions was obtained from T.J. Koerner (Hardy and Strauss 1988). By use of standard cloning techniques (Maniatis et al. 1982), restriction fragments from cDNA 5 (Celniker and 
Celniker et al.

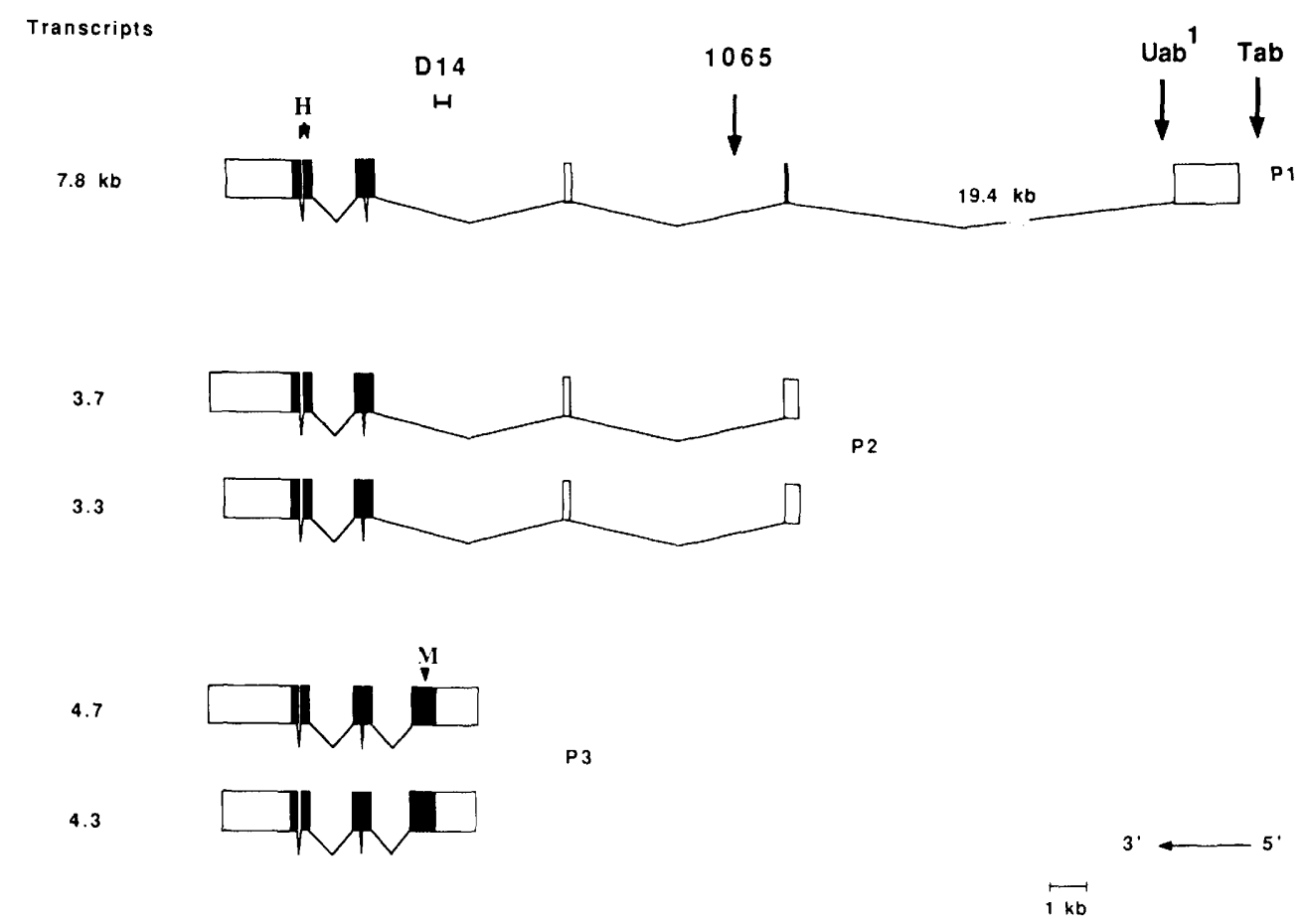

Figure 9. Putative transcript organization of the $A b d-B$ domain. The different exons are shown (open boxes). The ORF is indicated (filled boxes). The homeo box $(H)$ spans exons 7 and 8 . The $M$ repeat $(M)$ is located in exon 4 . Three putative promoters are indicated P1, P2, and P3. The large intron is not drawn to scale, but the size is indicated in kilobases. Mutant breakpoints are designated with arrows and the D14 deletion indicated by the bracket.

Lewis 1987) were filled-in, low-melting-point gel-purified, and ligated into the filled-in EcoRI site of pATH 1. Eight plasmids containing the inserts were identified by colony hybridization (Grunstein and Hogness 1975). After screening by restrictionfragment analysis, three were found to have the proper orientation. The insertion junction of one of these (clone plAbdb) was sequenced (Maxam and Gilbert 1980) to confirm the reading frame.

\section{Expression and purification of trpE fusion protein}

Cultures of MC1061 cells containing the hybrid gene fusion constructs were grown overnight in M9CA (Maniatis et al. 1982) containing $50 \mu \mathrm{g} / \mathrm{ml}$ ampicillin and $10 \mu \mathrm{g} / \mathrm{ml}$ tryptophan at $37^{\circ} \mathrm{C}$. The cultures were diluted $1: 10$ in M9CA containing ampicillin and grown for $1 \mathrm{hr}$ at $30^{\circ} \mathrm{C} .3 \beta$-Indoleacrylic acid (Sigma, $10 \mathrm{mg} / \mathrm{ml}$ in $100 \% \mathrm{EtOH}$ ) then was added at a concentration of $5 \mu \mathrm{g} / \mathrm{ml}$, and the cultures were allowed to grow for an additional $2 \mathrm{hr}$ at $30^{\circ} \mathrm{C}$. The cells were pelleted at $5000 \mathrm{~g}$ for $10 \mathrm{~min}$ at $4^{\circ} \mathrm{C}$. The supernatant was drained carefully and the pellet was resuspended in cracking buffer $[0.01 \mathrm{M}$ sodium phosphate $\{\mathrm{pH} 7.2\}, 1 \% \beta$-mercaptoethanol, $1 \%$ SDS, $6 \mathrm{~m}$ urea $)$. The mixture was heated at $37^{\circ} \mathrm{C}$ for $2 \mathrm{hr}$ to solubilize the protein. The yield of fusion protein was estimated to be $0.2-1.0 \mathrm{mg} / \mathrm{ml}$.

\section{Preparation of monoclonal antibodies}

Fusion protein was semipurified before injection. From 1 to 5 $\mathrm{ml}$ of whole-cell lysate was electrophoresed on a $12.5 \%$, discontinuous, SDS-polyacrylamide gel and visualized by placing the gel in $0.25 \mathrm{M} \mathrm{KCl}$ at $4^{\circ} \mathrm{C}$ for $10 \mathrm{~min}$. The fusion protein band was excised, placed in dialysis tubing, and electroeluted at 30 mA overnight. After extensive dialysis against distilled $\mathrm{H}_{2} \mathrm{O}$, containing phenylmethylsulfonyl fluoride (PMSF) at 17.4 $\mu \mathrm{g} / \mathrm{ml}$, the protein was lyophilized. The lyophilized protein was resuspended in 200-400 $\mu \mathrm{l}$ of $\mathrm{H}_{2} \mathrm{O}$. Robertsonian mice were immunized with $20-60 \mu \mathrm{g}$ of fusion protein intraperitoneally in complete Ribi adjuvant. They were boosted two times at three week intervals and again 8 weeks later. A final boost was given after an additional 2 weeks; 4 days later, the spleen was removed for fusion with FOX-NY myeloma cells. A total of $6.24 \times 10^{7}$ spleen cells was fused with $3.12 \times 10^{7}$ myeloma cells. Then $3 \times 10^{5}$ cells per well of a 96-well microtiter dish were plated in RPMI containing $10 \%$ fetal calf serum, $10 \mathrm{mM}$ HEPES, $2 \mathrm{mM}$ glutamate, $1 \mathrm{~mm}$ sodium pyruvate, and $10 \mathrm{U} / \mathrm{ml}$ penicillin and streptomycin. The 420 clones were screened on protein dot blots against both semipurified fusion protein and semipurified $\operatorname{trp} E$ protein. The 35 dot-blot-positive clones were rescreened on Western protein blots, three positives of which were cloned subsequently by limited dilution. Culture supernatants were used for immunological assays.

\section{Protein blots}

Fusion and 4- to 20-hr embryonic nuclear proteins were isolated in the presence of PMSF (prepared as described by Heberlein and Tjian 1988), were separated in one dimension by SDS-gel electrophoresis (Laemmli 1970) or in two dimensions by nonequilibrium $\mathrm{pH}$ gel electrophoresis (NEPHGE) combined with SDS gradient gel electrophoresis (O'Farrell et al. 1977). The NEPHGE gels $(\mathrm{pH}$ range: $6-10)$ were run for $\sim 2000 \mathrm{~V}$-hr followed by a 6 -hr run on a $5-15 \%$ SDS gradient gel at $30 \mathrm{~mA}$. In both cases, the proteins were transferred electrophoretically to nitrocellulose filters $(20$ volts overnight in a $0.01 \%$ boric acid, $0.015 \%$ sodium borate buffer). The filters were blocked for $1-4$ hr in $10 \%$ fetal calf serum, $0.05 \%$ Tween-20, $10 \mathrm{mM}$ Tris $(\mathrm{pH}$ 7.51, $129 \mathrm{~mm} \mathrm{NaCl}, 5 \mathrm{~mm} \mathrm{KCl}, 1 \mathrm{~mm}$ EGTA, 2\% BSA, and $0.03 \%$ sodium azide and then incubated with primary antibody 
for 3-15 hr. Then the blots were washed in three changes of gelatin buffer $[0.5 \%$ gelatin, $12 \mathrm{mM}$ Tris $(\mathrm{pH} 7.5), 0.75 \mathrm{M} \mathrm{NaCl}$, $5 \mathrm{mM}$ EDTA, and $0.03 \%$ sodium azidel and incubated with alkaline phosphatase-conjugated, goat anti-mouse secondary antibodies for $1 \mathrm{hr}$. The blots were washed again in gelatin buffer and the antigen was localized using a solution containing color development substrates, according to the Promega Protoblot system.

\section{Immunolocalization methods}

Staged embryos were dechorionated in $50 \%$ bleach, washed extensively in $0.02 \%$ Triton X-100, and devitellinized using biphasic extraction essentially as described by Mitchison and Sedat (1983). The primary antibody for $A b d-B$ was a mouse monoclonal (1 A2E9); $U b x$ was a mouse monoclonal (White and Wilcox 1985). Horseradish peroxidase was from Cooper Biochemical. Secondary antibodies conjugated to fluorescein isothiocyanate (FITC) and rhodamine were from Cappel. For immunoperoxidase or immunoalkaline phosphatase labeling, we obtained the appropriate $A B C$ kits from Vectastain. Nuclei were stained using DAPI at $1 \mu \mathrm{g} / \mathrm{ml}$ before equilibrating the embryos in the anti-quenching PDA glycerol mounting solution. Immunohistochemically stained embryos were dehydrated in a graded ethanol series, cleared in xylene, mounted in Permount and photographed using Nomarski interference contrast microscopy.

\section{Acknowledgments}

We are indebted to Susan Ou, of the Caltech Monoclonal Facility, under the direction of Paul Patterson, for producing excellent $A b d-B$ monoclonal antibodies. We thank John Pollock for assistance with the CNS dissections; Seymour Benzer for use of his laboratory facilities; Dennis Ballinger, Charles Rozek, Elizabeth Gavis, Welcome Bender, and Howard Lipshitz for helpful discussions; Richard Mann and David Hogness for sending the $U b x$ antibody loriginally from $R$. White and $M$. Wilcox); Marianne Bienz for communicating sequence data on the $i a b-8$ cDNA pH1 89 in advance of publication; Scott Rosenfeld for sequencing most of cDNA 5; Tom Kornberg for providing the en antibody; Joan Roach for technical assistance; and Charles Rozek and Joanne Topol for commenting on the manuscript. This work was supported by research grants to E.B.L. from the National Institutes of Health (HD-06331), and PR-07003) Program Project Grant (NIH GM-40499), the American Cancer Society (000543), the March of Dimes (1-10229) and the Lucille P. Markey Charitable Trust.

\section{References}

Akam, M. 1987. The molecular basis for metameric pattern in the Drosophila embryo. Development 101: 1-22.

Akam, M., I. Dawson, and G. Tear. 1988. Homeotic genes and the control of segment diversity. Development 104: 123133.

Beachy, P.A., S.L. Helfand, and D.S Hogness. 1985. Segmental distribution of Bithorax Complex proteins during Drosophila development. Nature 313: 545-551.

Beachy, P.A., M.A. Krasnow, E.R. Gavis, and D.S. Hogness. 1988. An Ultrabithorax protein binds sequences near its own and the Antennapedia P1 promoters. Cell 55: 10691081.

Bender, W., M. Akam, F.A. Karch, P.A. Beachy, M. Peifer, P. Spierer, E.B. Lewis, and D.S. Hogness. 1983. Molecular genetics of the Bithorax Complex in Drosophila melanogaster. Science 221: 23-29.
Boncinelli, E., A. Simeone, A. La Volpe, A. Faiella, V. Fidanza, D. Acampora, and L. Scotto. 1988. Organization of human homeo box genes. Human Reproduction 3: 880-886.

Breier, G., M. Bucan, U. Francke, A.M. Colberg-Poley, and P. Gruss. 1988. Primary structure and developmental expression pattern of Hox 3.1, a member of the murine Hox 3 homeo box gene cluster. EMBO J. 7: 1329-1336.

Campos-Ortega, J.A. and V. Hartenstein. 1985. The embryonic development of Drosophila melanogaster. Springer-Verlag, Berlin.

Casanova, J. , E. Sanchez-Herrero, and G. Morata. 1986. Identification and characterization of a parasegment specific regulatory element of the Abdominal-B gene of Drosophila. Cell 47: $627-636$.

Casanova, J. and R.A.H. White. 1987. Trans-regulatory function in the Abdominal-B gene of the Bithorax Complex. Development 101: 117-122.

Celniker, S.E. and E.B. Lewis. 1987. Transabdominal: a dominant mutant of the Bithorax Complex produces a sexually dimorphic segmental transformation in Drosophila. Genes Dev. 1: 111-123.

Cohen, S.M., G. Brönner, F. Küttner, G. Jürgens, and H. Jäckle. 1989. Distal.less encodes a homeo domain protein required for limb development in Drosophila. Nature 338: 432-434.

DeLorenzi, M., N. Ali, G. Saari, C. Henry, M. Wilcox, and M. Bienz. 1988. Evidence that the Abdominal-B r element function is conferred by a trans-regulatory homeo protein. EMBO I. 7: 3223-3232.

Desplan, C., J. Theis, and P.H. O'Farrell. 1985. The Drosophila developmental gene, engrailed, encodes a sequence-specific DNA binding activity. Nature 318: 630-635.

Duboule, D. and P. Dolle. 1989. The murine Hox gene network: its structural and functional organization resembles that of Drosophila homeotic genes. EMBO /. (in press).

Duncan, I. 1987. The Bithorax Complex. Annu. Rev. Genet. 21: $285-319$.

Duncan, I. and E.B. Lewis. 1982. Genetic control of body segment differentiation in Drosophila. Symp. Soc. Dev. Biol. 40: $533-544$.

Garber, R.L., A. Kuroiwa, and W.J. Gehring. 1983. Genomic and cDNA clones of the homeotic locus Antennapedia in Drosophila. EMBO J. 2: 2027-2036.

Gaunt, S.J., P.T. Sharpe, and D. Duboule. 1988. Spatially restricted domains of homeo-gene transcripts in mouse embryos: relation to a segmented body plan. Development 104: $169-179$.

Gay, N.J., S.J. Poole, and T.B. Kornberg. 1988. The Drosophila engrailed protein is phosphorylated by a serine-specific protein kinase. Nucleic Acids Res. 16: 6637-6647.

Grunstein, M. and D. Hogness. 1975. Colony hybridization: A method for the isolation of cloned DNAs that contain a specific gene. Proc. Natl. Acad. Sci. 77: 3961.

Harding, K., C. Weeden, W. McGinnis, and M. Levine. 1985. Spatially regulated expression of homeotic genes in Drosophila. Science 229: 1236-1242.

Hardy, W.R. and J. Strauss. 1988. Processing the nonstructural polyproteins of sindbis virus: study of the kinetics in vivo by using monospecific antibodies. /. Virology 62: 998-1007.

Heberlein, U. and R. Tjian. 1988. Temporal pattern of alcohol dehydrogenase gene transcription reproduced by Drosophila stage-specific embryonic extracts. Nature 331: 410-415.

Hopp, T.P. and K.R. Woods. 1981. Prediction of protein antigenic determinants from amino acid sequences. Proc. Natl. Acad. Sci. 78: 3824-3828.

Ingham, P., D. Ish-Horowiscz, and K. Howard. 1986. Correlative changes in homeotic and segmentation gene expression 
in Krüppel mutant embryos in Drosophila. EMBO $I$. 5: $1659-1665$.

Ingham, P. and A. Martinez-Arias. 1986. The correct activation of Antennapedia and Bithorax Complex genes requires the fushi-tarazu gene. Nature 324: 592-597.

Karch, F., B. Weiffenbach, M. Peifer, W. Bender, I. Duncan, S. Celniker, M. Crosby, and E.B. Lewis. 1985. The abdominal region of the Bithorax Complex. Cell 43: 81-96.

Kaufman, T.C., R. Lewis, and B. Wakimoto. 1980. Cytogenetic analysis of chromosome 3 in Drosophila melanogaster: the homeotic gene complex in polytene chromosomal interval 84A,B. Genetics 94: 115-133.

Krause, J.M., R. Klemnz, and W.J. Gehring. 1988. Expression, modification and localization of the fushi-tarazu protein in Drosophila embryos. Genes Dev. 2: 1021-1036.

Kuziora, M.A. and W. McGinnis. 1988. Different transcripts of the Drosophila $A b d-B$ gene correlate with distinct genetic sub-functions. $E M B O$ /. 7: 3233-3244.

Laemmli, U.K. 1970. Cleavage of structural proteins during the assembly of the head of bacteriophage T4. Nature 227: 680685.

Laughon, A. and M.P. Scott. 1984. Sequence of a Drosophila segmentation gene: protein structure homology with DNAbinding proteins. Nature 310: 25-31.

Levine, M., K. Harding, C. Weeden, H. Doyle, T. Hoey, and H. Radomska. 1985. Expression of the homeo box gene family in Drosophila. Cold Spring Harbor Symp. Quant. Biol. 50: 209-222.

Lawrence, P.A. and A. Martinez-Arias. 1985. The cell lineage of segments and parasegments in Drosophila. Philos. Trans. $R$. Soc. London Ser. B 312: 83-90.

Lewis, E.B. 1978. A gene complex controlling segmentation in Drosophila. Nature 276: 565-570.

Macdonald, P.M. and G. Struhl. 1986. A molecular gradient in early Drosophila embryos and its role in specifying the body pattern. Nature 324: $537-545$

Maniatis, T., E.F. Fritsch, and J. Sambrook. 1982. Molecular cloning: A laboratory manual. Cold Spring Harbor Laboratory, Cold Spring Harbor, New York.

Maxam, A.M. and W. Gilbert. 1980. Sequencing with base-specific chemical cleavages. Methods Enzymol. 65: 497-559.

Mitchison, T.J. and J. Sedat. 1983. Localization of antigenic determinants in whole Drosophila embryos. Dev. Biol. 99: $261-264$.

Mlodzik, M., A. Fjose, and W.J. Gehring. 1988. Molecular structure and spatial expression of a homeo box gene from the labial region of the Antennapedia Complex. EMBO /. 7: 2569-2578.

Nüsslein-Volhard, C. and E. Wieschaus. 1980. Mutations affecting segment number and polarity in Drosophila. Nature 287: 795-801.

O'Farrell, P.Z., H.M. Goodman, and P.H. O'Farrell. 1977. High resolution two-dimensional electrophoresis of basic as well as acidic proteins. Cell 12: 1133-1142.

Proudfoot, N.J. and G.G. Brownlee. 1976. 3' Non-coding region sequences in eukaryotic mRNA. Nature 263: 211-214.

Regulski, R., K. Harding, R. Kostriken, F. Karch, M. Levine, and W. McGinnis. 1985. Homeo box genes of the Antennapedia and Bithorax Complexes of Drosophila. Cell 43: 71-80.

Rubin, M.R., W. King, L.E. Toth, I.S. Sawczuk, M.S. Levine, P. D'Eustachio, and M.C. Nguyen-Huu. 1987. Murine Hox-1.7 homeo-box gene: cloning, chromosomal location, and expression. Mol. Cell. Biol. 7: 3836-3841.

Sanchez-Herrero, E., J. Casanova, S. Kerridge, and G. Morata. 1985a. Anatomy and function of the Bithorax Complex of
Drosophila. Cold Spring Harbor Symp. Quant. Biol. 50: $165-172$.

Sanchez-Herrero, E., I. Vernos, R. Marco, and G. Moreta. 1985b. Genetic organization of Drosophila Bithorax Complex. $\mathrm{Na}$ ture 313: 108-113.

Sanchez-Herrero, E. and M.A. Crosby. 1988. The Abdominal-B gene of Drosophila melanogaster: overlapping transcripts exhibit two different spatial distributions. EMBO $\quad$. 7: 2163-2173.

Sanger, F., S. Miklen, and A.R. Coulson. 1977. DNA sequencing with chain terminating inhibitors. Proc. Natl. Acad. Sci. 74: $5463-5467$.

Scott, M.P., A.J. Weiner, T.I. Hazelrigg, B.A. Polisky, V. Pirrotta, F. Scalenche, and T.C. Kaufman. 1983. The molecular organization of the Antennapedia locus of Drosophila. Cell 35: 763-776.

Scott, M.P., J.W. Tamkun, and G.W. Hartzell. 1988. The structure and function of the homeo domain. $B B A$ Reviews on Cancer. (in press).

Shepherd, J.C., W. McGinnis, A.E. Carrasco, E.M. De Robertis and W.J. Gehring. 1984. Fly and frog homeo domains show homologies with yeast mating type regulatory proteins. $\mathrm{Na}$ ture 310: 70-71.

Spindler, K.R., D. Rosser, and A. Berk. 1984. Analysis of adenovirus transforming proteins from early regions $1 \mathrm{~A}$ and $\mathrm{BB}$ with antisera to inducible fusion antigens produced in Escherichia coli. J. Virol. 49: 132-141.

Staden, R. 1984. Measurements of the effects that coding for a protein has on a DNA sequence and their use for finding genes. Nucleic Acids Res. 12: 551-567.

Struhl, G. 1981. A gene product required for the correct initiation of segment determination in Drosophila. Nature 293: 36-41.

Struhl, G. and M. Akam. 1985. Altered distributions of Ultrabithorax transcripts in extra sex combs mutant embryos of Drosophila. EMBO I. 4: 3259-3264.

Struhl, G. and R.A.H. White. 1985. Regulation of the Ultrabithorax gene of Drosophila by other Bithorax Complex genes. Cell 43: 507-519.

Tiong, S., L.M. Bone, and J.R. Whittle. 1985. Recessive lethal mutations within the Bithorax Complex in Drosophila. Mol. Gen. Genet. 200: 335-342.

Wedeen, C., K. Harding, and M. Levine. 1986. Spatial regulation of Antennapedia and bithorax gene expression by the polycomb locus in Drosophila. Cell 44: 739-748.

Wharton, K.A., B. Yedvobick, V.G. Finnerty, and S. ArtavanisTsakonas. 1985. opa: a novel family of transcribed repeats shared by the Notch locus and other developmentally regulated loci in Drosophila melanogaster. Cell 40: 55-62.

White, R.A.H. and R. Lehmann. 1986. A gap gene, hunchback, regulates the spatial expression of Ultrabithorax. Cell 47: $311-321$.

White, R.A.H. and M. Wilcox. 1984. Protein products of the Bithorax Complex in Drosophila. Cell 39: 163-171.

\section{Note}

Sequence data described in this paper have been submitted to the EMBL/GenBank Data Libraries under accession number X16134 Abd-B P3. 


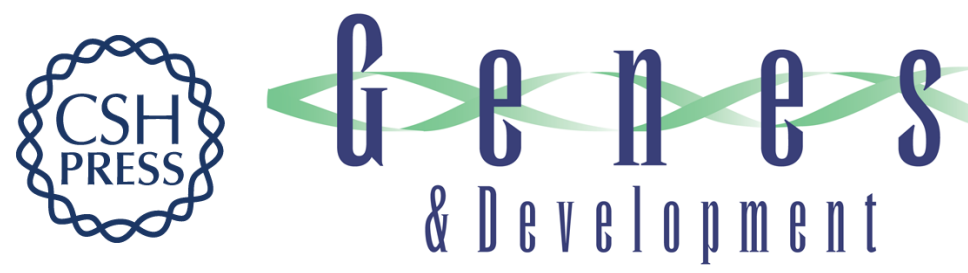

\section{The molecular genetics of the bithorax complex of Drosophila: characterization of the products of the Abdominal-B domain.}

S E Celniker, D J Keelan and E B Lewis

Genes Dev. 1989, 3:

Access the most recent version at doi:10.1101/gad.3.9.1424

References This article cites 59 articles, 15 of which can be accessed free at:

http://genesdev.cshlp.org/content/3/9/1424.full.html\#ref-list-1

License

Email Alerting

Service

Receive free email alerts when new articles cite this article - sign up in the box at the top right corner of the article or click here.

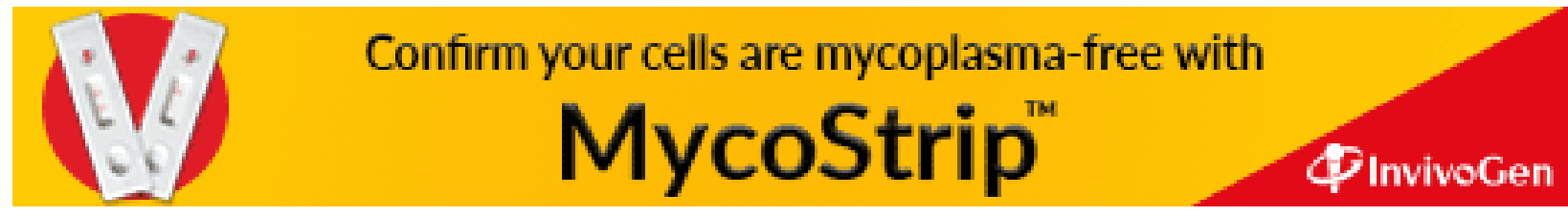

